\title{
Characteristics of Nickel Boron Coatings prepared by Direct Current Electrodeposition Technique
}

\author{
Chien-Rong Chang ${ }^{1}$, Kung-Hsu, Hou ${ }^{2, *}$, Ming-Der Ger ${ }^{3}$, Jee-Ray Wang ${ }^{4, * *}$ \\ ${ }^{1}$ School of Defense Science, Chung Cheng Institute of Technology, National Defense University, \\ Taiwan \\ ${ }^{2 *}$ Department of Power Vehicle and Systems Engineering, Chung Cheng Institute of Technology, \\ National Defense University \\ ${ }^{3}$ Department of Chemical \& Materials Engineering, Chung Cheng Institute of Technology, National \\ Defense University, Taoyuan, Taiwan \\ $4^{* *}$ Department of Automation Engineering \& Institute of Mechatronoptic, Chienkuo Technology \\ University, Changhua, Taiwan \\ E-mail: khoucloud@gmail.com, khou@ndu.edu.tw, jrwang@ctu.edu.tw
}

doi: $10.20964 / 2017.03 .17$

Received: 12 November 2016 / Accepted: 9 January 2017 / Published: 12 February 2017

In this research, Ni-B coatings with different boron content (1.85 to 18.63 at.\%) were produced by direct current electrodeposition technique and from a bath containing trimethylamineborane (TMAB) at $0.06 \mathrm{M}$. The influence of deposition current density on the composition, surface morphology, grain size, hardness, corrosion resistance and wear properties of the coatings was investigated. Our result found that the boron content in the coatings decreases significantly with increasing deposition current density. The further analysis showed the great influence of boron content on the grain size and hardness of the coating. A maximum hardness of about $954 \mathrm{Hv}$ was obtained for a nanocrystalline NiB coating with a boron content of 4.38 at.\%, while the amorphous-like Ni-B coating at a boron content of 18.63 at.\% has a lower hardness as compared to those nanocrystalline Ni-B coatings. The potentiodynamic polarization measurement showed that the Ni-B coatings had higher corrosion resistance than that of pure nickel coating. Grain size is the main factor affecting corrosion resistance of the coatings. Wear test results show that the wear resistance of $\mathrm{Ni}-\mathrm{B}$ coatings is governed by the microhardness. An increase in the hardness of the Ni-B coating leads to promotion of the wear resistance.

Keywords: Ni-B coatings; Electrodeposition; Corrosion resistance; Wear resistance 
(C) 2017 The Authors. Published by ESG (www.electrochemsci.org). This article is an open access article distributed under the terms and conditions of the Creative Commons Attribution license (http://creativecommons.org/licenses/by/4.0/). 